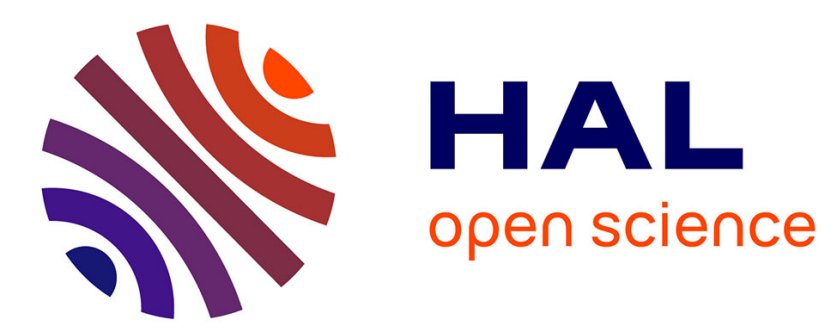

\title{
Endogenous Growth in Production Networks
}

Stanislao Gualdi, Antoine Mandel

\section{- To cite this version:}

Stanislao Gualdi, Antoine Mandel. Endogenous Growth in Production Networks. 2016. halshs01382483

\section{HAL Id: halshs-01382483 \\ https://shs.hal.science/halshs-01382483}

Submitted on 17 Oct 2016

HAL is a multi-disciplinary open access archive for the deposit and dissemination of scientific research documents, whether they are published or not. The documents may come from teaching and research institutions in France or abroad, or from public or private research centers.
L'archive ouverte pluridisciplinaire HAL, est destinée au dépôt et à la diffusion de documents scientifiques de niveau recherche, publiés ou non, émanant des établissements d'enseignement et de recherche français ou étrangers, des laboratoires publics ou privés. 


\section{Documents de Travail du PANTHÉN SORBONNE Centre d'Economie de la Sorbonne}
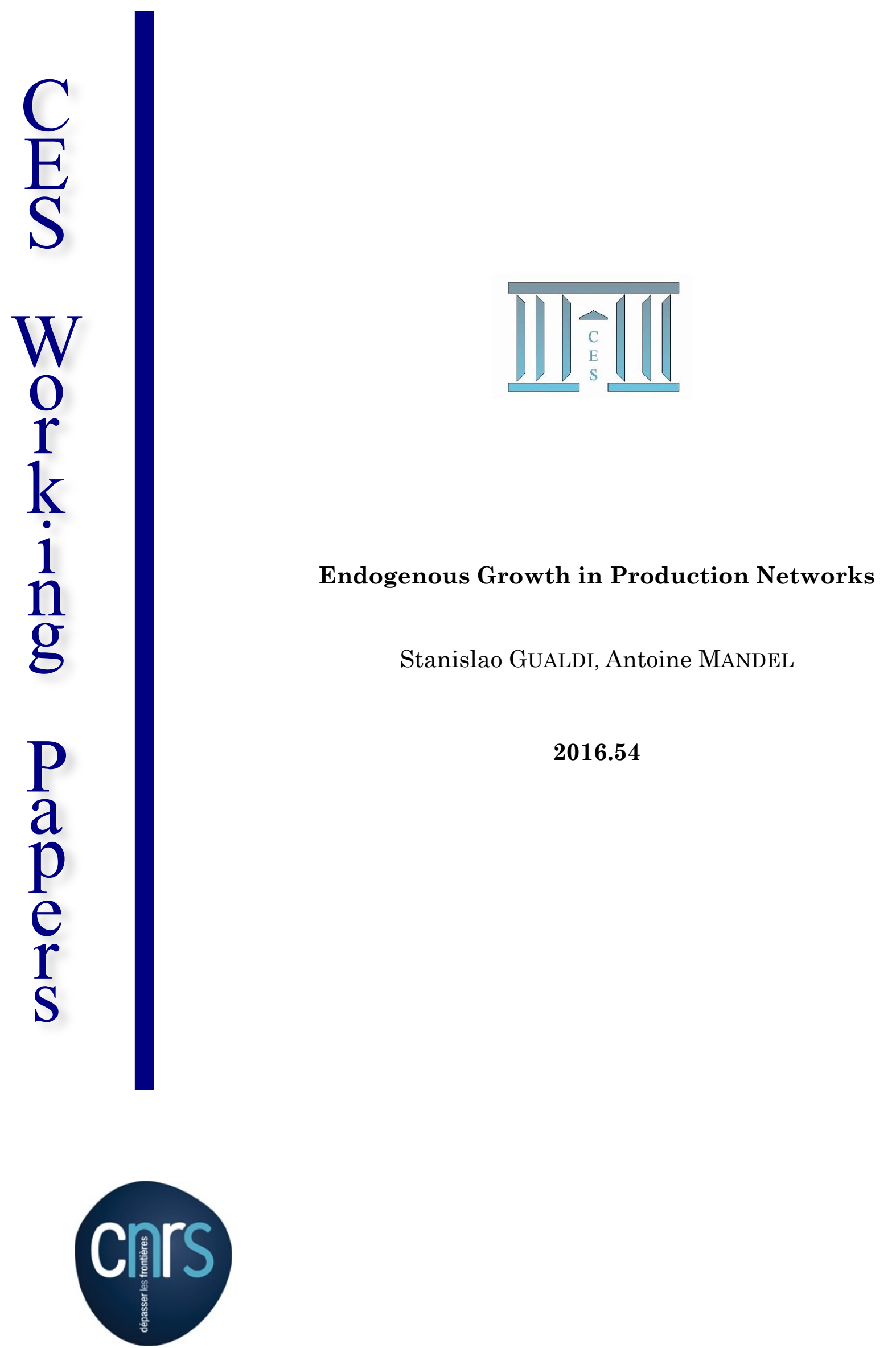


\title{
Endogenous Growth in Production Networks
}

\author{
Stanislao Gualdi ${ }^{\ddagger}$ and Antoine Mandel ${ }^{\S}$
}

April 29, 2016

\begin{abstract}
We investigate the interplay between technological change and macroeconomic dynamics in an agent-based model of the formation of production networks. On the one hand, production networks form the structure that determines economic dynamics in the short run. On the other hand, their evolution reflects the long-term impacts of competition and innovation on the economy. We account for process innovation via increasing variety in the input mix and hence increasing connectivity in the network. In turn, product innovation induces a direct growth of the firm's productivity and the potential destruction of links. The interplay between both processes generate complex technological dynamics in which phases of process and product innovation successively dominate. The model reproduces a wealth of stylized facts about industrial dynamics and technological progress, in particular the persistence of heterogeneity among firms and Wright's law for the growth of productivity within a technological paradigm. We illustrate the potential of the model for the analysis of industrial policy via a preliminary set of policy experiments in which we investigate the impact on innovators' success of feed-in tariffs and of priority market access.
\end{abstract}

\section{Introduction}

In contrast with the extremely detailed description of markets and financial interactions that have been developed in the recent literature [see e.g Dawid et al. 2014, Dosi et al., 2015, and references below], the representation of the innovation process has remained relatively stylized in agent-based macro-economic models. It is usually assumed that technological progress materializes at the micro level through (exponential) growth in the productivity of capital goods over time. Hence the models abstract away from the micro-economics of technological change and fail to inscribe technological processes in the economic state space.

\footnotetext{
${ }^{\ddagger}$ CentraleSupélec, stanislao.gualdi@gmail.com

$\S$ Paris School of Economics, Université Paris I Panthéon-Sorbonne,antoine.mandel@univpais1.fr
} 
This strongly contrasts with the detailed analysis of the innovation process that has been developed in the evolutionary literature. More importantly, this leaves an important gap open in terms of policy analysis. Indeed, without a detailed representation of innovation and technological processes, agent-based models can hardly be used to analyze policies that involve large impacts on technologies, first and foremost climate change mitigation, which possibly is the most important long-term challenge faced by contemporary economies.

In order to fill part of this gap, we introduce in this paper an agent-based model where technological evolution is modeled in details through the evolution of production networks. These networks provide a detailed description of the technological and commercial relationships between firms and can easily be mapped to an input-output table. On the one hand, they form the structure that determines economic dynamics in the short run. On the other hand, their evolution reflects the long-term impacts of competition and innovation on the economy.

Accordingly, in our model, once the network is given the dynamics of prices and output follow from the application of simple behavioral rules. Conversely, the evolution of the network reflects the long-term dynamics of the economy driven by competition and innovation processes. Competition materializes via redirections (rewiring) of relationships between firms and hence induce an "horizontal" evolution of the network. Innovation and technological change, which form the core of our model, materialize both via radical (product) innovation and incremental (process) innovation. Radical innovation occurs through the discovery by firms of new technological paradigms that lead to increasingly efficient products. Process innovation materializes, within a technological paradigm, through diversification of the input mix. The interplay between these processes drives the evolution of the network: process innovation through diversification leads to increasing connectivity among firms while radical innovations might render obsolete a very mature technology and hence induce a decrease in connectivity. The input-output structure of the model evolves accordingly. We hence approach what is according to Dosi and Nelson, 2010] a quite challenging modeling frontier [that] regards the explicit representation of evolving problemsolving procedures, constrained by paradigm-shaped 'grammars' and their ensuing dynamics in the more familiar space of input/output coefficients.

The model is able to reproduce key stylized facts of industrial dynamics with respect to the distribution of firms' growth rates and size, the persistence of heterogeneity in productivity among firms or the structure of production networks. Also, our representation of process/incremental innovation is consistent with Wright's law Wright, 1936. When combined with radical innovation and imitation à la Nelson and Winter (1982), it leads to the emergence of endogenous growth paths and of technology-driven business cycles. These cycles are characterized by the transition between phases of radical/product and incremental/process innovation akin to the one described in the Utterback-Abernathy model [see Utterback, 1994. In summary, the model is able to reproduce a rich set of stylized facts and provide bridges between innovation and endogenous growth theories. 
Hence, we provide an agent-based framework fit for the analysis of large technological changes in the economy and potentially of innovation policies. In this latter respect, we perform a first series of policy experiments in which we investigate the impacts of price-based measures, akin to feed-in tariffs, and quantity-based measures, i.e preferential access to the market, on the survival rate of radical innovators and the growth rate of the economy. Our results emphasize that the impacts of such policy measures heavily depend on the strucuture of externalities in the innovation process.

The remaining of the paper is organized as follows. In section 2, we review the related literature. Section 3 gives a detailed description of the model. Section 4 investigates the impact of different innovation process on the structure of the production network and on macro-economic dynamics. Section 5 , highlights the behavior of the model in a series of policy experiments and section 6 concludes.

\section{Related Literature}

In most existing agent-based macro-economic models, the representation of the production process is rather stylized and involves only labor and capital, possibly of heterogeneous kinds. Intermediary consumption or the details of the "recipes" used in production are usually not accounted for. Accordingly, technological progress is embedded in physical capital whose vintages grow in productivity over time. This approach is rather generic and followed in particular in Dosi et al. 2010, 2013, 2015, Dawid et al., 2011, 2014] or Ciarli et al. 2010. Mandel et al. 2010 and Wolf et al. [2013] uses a different representation of the production process that accounts for intermediary consumption but productivity growth is driven by cumulative investment and hence totally decoupled from the specifics of the production process.

In contrast, in our setting, growth in productivity is essentially linked to changes in the production process and correlatively in the production network. Hence our approach is closely related to the evolutionary and complex systems literature that have focused on the dynamics of technology. This literature is extensively surveyed in Frenken, 2006b and Dosi and Nelson, 2010. In particular Frenken, 2006b identifies three main approaches in the literature: fitness landscape models [e.g Kauffman et al., 2000], percolation models [e.g Silverberg and Verspagen, 2005, and production recipes models [e.g Auerswald et al. 2000 . The most relevant contributions from our perspective are those that model the evolution of "production recipes" such as Auerswald et al. 2000, Frenken 2006a] and more recently [McNerney et al., 2011]. These contributions are strongly rooted in an engineering/design perspective and, following Kauffman 1993, emphasize the interdependencies among the elements of designs as the key parameter determining the dynamics of technologies. In particular, McNerney et al. 2011 emphasizes that the interplay between complexity of the design, measured via the degree of interdependency, and the increasing difficulty in improving components leads to the emergence of Wright's law for 
the rate of technological progress [see Wright, 1936, Arrow, 1962, in this latter respect]. Our approach is slightly more aggregate and distant from engineering considerations as we map the technological process directly in the input-output space. This allows us to provide the macro-economic closure that misses in the "production recipes" contributions. With respect to Wright's law, we obtain results similar to those of [McNerney et al., 2011.

We go beyond process innovation through the introduction of radical innovation, which leads to the discovery of new technological paradigms and growth in products' productivity. In our micro-founded setting, combining product and process innovation is required to induce exponential growth. This provides an interesting contrast with standard approaches in the endogenous growth literature. Except in degenerate case [see d'Autume and Michel, 1993, growth models à la Arrow 1962 based on Wright's law are not conductive to exponential growth. Hence endogenous growth models à la Romer 1990 requires the variety of inputs in the production process to grow exponentially in order to generate sustained growth. This assumption might appear as innocuous when the production process is represented at the aggregate level but leads to major inconsistencies with empirical regularities if implemented in our micro-economic setting. Hence, the emergence of exponential growth requires more radical forms of product innovation of the kind considered in "Schumpeterian" growth models à la Aghion and Howitt 1992. Whereas, this "schumpeterian" literature considers that the growth process is driven by a succession of monopolies, in our setting different technological "paradigms" at different levels of maturity and diversification co-exist. This allows to preserve competition and heterogeneity in productivity among firms, consistently with empirical observations.

The hybrid nature of our model echoes the considerations about variety put forward in [Saviotti et al., 1996], in particular Saviotti's second hypothesis according to which Variety growth, leading to new sectors, and productivity growth in pre-existing sectors are complementary and not independent aspects of economic development. More broadly, we could argue that we operationalize, via a network-based approach, Saviotti and Pyka [2008]'s concept of variety, which is broader than this of product variety since it refers to the extent of diversification in the economic system.

Finally, our network perspective on the productive system relates to an expanding stream of literature using both agent-based Bak et al. 1987, Weisbuch and Battiston, 2007, Battiston et al., 2007 and general equilibrium methods Acemoglu et al., 2012, Carvalho, 2014]. This literature hasn't yet approached the issue of growth and technological change but for the notable exception of Carvalho and Voigtländer 2014. These authors put forward a new stylized fact at both the sector and the firm level: producers are more likely to adopt inputs that are already used - directly or indirectly - by their current suppliers. They provide theoretical foundations for this process using the network formation model of Jackson and Rogers 2007], which they adapt by considering that new products/firms entering the economy draw a first part of their inputs at random and a second part from the connections of these drawn in the first phase. Hence their approach is much more precise than ours with respect to the direction of 
technological change. Yet, our approach is complementary to theirs as it allows the macro-economic closure of the model and account for the interplay between product and process innovations.

\section{The model}

\subsection{Technological structure}

We represent the dynamics of a network consisting of (at most) $m$ firms distributed over $S$ industrial sectors and one aggregate household. We denote the set of firms by $M=\{1, \cdots, m\}$, the household by the index 0 and the set of agents by $N=\{0, \cdots, m\}$. Time is discrete, indexed by $t \in \mathbb{N}$. The network of supply relationships is represented by an adjacency matrix $A^{t}$ such that $a_{i, j}^{t}=1$ if and only if $j$ is a supplier of $i$ (and $a_{i, j}^{t}=0$ otherwise). The network evolves over time under the influence of competition and innovation.

Production processes are linked to the structure of the network via production functions, which are assumed to be of the C.E.S type as in the literature on monopolistic competition on the intermediate goods markets (see Ethier 1982, Romer [1990]) . More precisely, given a production network $A$, the set of suppliers of firm $i$ is $\Sigma_{i}(A):=\left\{j \in M \mid a_{i, j}=1\right\}$ and its production possibilities are given by the function:

$$
f_{i}^{t}\left(x_{0},\left(x_{j}\right)_{j \in \Sigma_{i}(A)}\right):=x_{0}^{\gamma}\left(\sum_{j \in \Sigma_{i}(A)}\left(e_{j}^{t} x_{j}\right)^{\theta}\right)^{(1-\gamma) / \theta}
$$

where $\gamma \in(0,1)$ is the (nominal) share of labor in the input mix, $1 /(1-\theta)$ is the elasticity of substitution, $x_{0} \in \mathbb{R}_{+}$is the quantity of labor and $x_{j}$ the quantity of input $j$ used in the production process, and $e_{j}$ the productivity of input $j$.

Technological progress and the evolution of the network will then be closely intertwined. In particular, we shall assume throughout the paper that inputs are substitutable (i.e $\theta \in[0,1]$ ), and hence productivity will grow with the number of inputs/suppliers combined, that is with the density of the network. As a matter of fact, our results rely on the presence of increasing returns to variety rather than in the choice of a specific functional form for the production function or even the existence, at all, of a production function.

\subsection{Macro-economic closure}

We also attach the evolution of the economy to this of the network. Therefore, we follow Gualdi and Mandel 2015 and consider that the structure of the network determines the dynamics of the economy according to a set of behavioral rules. More precisely, let us denote by $A^{t}$ the adjacency structure of the network in period $t$ and let for every agent $i$, denote by $w_{i}^{t} \in \mathbb{R}_{+}$the wealth it holds, $q_{i}^{t} \in \mathbb{R}_{+}$the stock of output it has produced, $p_{i}^{t} \in \mathbb{R}_{+}$the price it sets for its output, and $\left(\alpha_{j}^{t}\right)_{j \in \Sigma_{i}\left(A^{t}\right)} \in \mathbb{R}_{+}^{\Sigma_{i}\left(A^{t}\right)}$ the input shares it chooses. The dynamics of the economy during period $t$ are then completely determined by the structure of 
the network. More precisely, the following sequence of events take place during a period:

1. Agents receive a nominal demand proportional to the wealths and the input shares of their connections.

2. Agents adjust their prices toward their market clearing value (at a rate $\left.\tau_{p} \in[0,1]\right)$.

3. Agents then produce according to the inputs they receive.

4. Agents adjust their input shares (at a rate $\tau_{w} \in[0,1]$ ) towards their costminimizing value.

A detailed representation of these dynamics is given in the appendix A.2. One of their salient property is that, if the network is fixed, the economy almost generically converges to the underlying general equilibrium [see Gualdi and Mandel, 2015 .

\subsection{Network Dynamics}

Now, our key focus in this paper is the joint evolution of the production network and of the economy. That is, the evolution of the adjacency structure $\left(A^{t}\right)^{t \in \mathbb{N}}$ over time and its impact on macro-economic dynamics. We shall consider two main drivers for this evolution: competition and innovation.

Competition materializes through the possibility for firms to periodically shift part of their business to more competitive suppliers. More precisely, we consider that at the end of each period, each firm independently receives the opportunity to change one of its suppliers with probability $\rho_{\text {chg }} \in[0,1]$. If this opportunity materializes for firm $i$ in period $t$, it selects randomly one of its suppliers $\bar{j}_{i}$ (in sector $S_{\bar{j}_{i}}$ ) and another random firm $j$ (in the same sector) among those to which it is not already connected. It then shifts its connection from firm $\bar{j}_{i}$ to firm $j$ if and only if the price (normalized per unit of productivity) of $j$ is less than the one of $\bar{j}_{i}$. In other words, the adjacency matrix $A^{t}$ evolves according to:

$$
\begin{gathered}
a_{i, \bar{j}_{i}}^{t+1}=\left\{\begin{array}{rr}
1 & \text { if } \frac{p_{\bar{j}_{i}}^{t}}{e_{\bar{j}_{i}}} \leq \frac{p_{j}^{t}}{e_{j}} \\
0 & \text { otherwise }
\end{array}\right. \\
a_{i, j}^{t+1}=1-a_{i, \bar{j}_{i}}^{t+1}
\end{gathered}
$$

The actual weight of the new connection is then determined according to an average over other suppliers' weights.

This competitive process leads to the evolution of the in-degree distribution of the network. In fact, as shown in Gualdi and Mandel [2015], competition leads to the emergence of a scale-free in-degree distribution because of two basic facts about the "economy" of suppliers' switches. On the one hand, the number of 
incoming business opportunities for a firm is independent of its size, i.e. firms gain link at a constant rate. On the other hand, the rate at which existing consumers may quit grows linearly with the size of the firm, i.e firms lose links proportionally to their degree. The balance between the flow of incoming and outgoing links lead to the emergence of a scale-free size distribution of incoming links.

Innovation materializes through two processes that account respectively for product and process innovation (and in an extended sense for radical and incremental innovation). More precisely, two element characterize a technology in our setting, the productivity $e \in \mathbb{R}_{+}$of the product produced and the input mix $v \in \mathbb{N}^{S}$, i.e the number of inputs from the different sectors used in the production process. In turn, a technological paradigm consists in a pair $(e, \Upsilon) \in \mathbb{R}_{+} \times 2^{\mathbb{N}^{S}}$ where $e$ represents the productivity of the product produced and $\Upsilon$ the set of input mixes that can be used to produce the product. In general, we shall assume that $\Upsilon$ is of the form $\Upsilon:=\left\{v \in \mathbb{N}^{S_{\Upsilon}} \mid S_{\Upsilon} \subset S \wedge v \leq \bar{v}\right\}$ where $\bar{v}$ represents the most complex (and hence productive) input mix within the paradigm. That is the production process can gain in efficiency through diversification up to a maximum amount of diversification, which is technology specific.

Let us consider a firm $i$ is that is using a technology $\left(e_{i}, v_{i}\right)$ within a paradigm $\left(e_{i}, \Upsilon_{i}\right)$. An incremental innovation for that firm consists in the adoption of a new input mix $\tilde{v}_{i}$ within the paradigm $\left(e_{i}, \Upsilon_{i}\right)$ such that $\tilde{v}_{i} \geq v_{i}$. A radical innovation consists in the adoption of a new technological paradigm $\left(\tilde{e}_{i}, \tilde{\Upsilon}_{i}\right)$ such that $\tilde{e}_{i} \geq e_{i}$ and of an input mix $\tilde{v}$ within the new paradigm.

Changes in the input mix materialize through the addition or the deletion of links. Hence, innovation is embedded within the network and technological progress materializes through the evolution of the network. As for the drivers of technological progress, we consider three possible avenues for productivity growth: process/incremental innovation, product/radical innovation and imitation as in the evolutionary model of Nelson and Winter(1982). More precisely each firm $i$ invests a fixed share $\theta$ of its revenues in $\mathrm{R}$ and $\mathrm{D}$ and this yields with probability $\rho_{i n n}$ per period an innovation, i.e every period, a share $\rho_{i n n}$ of firms are selected uniformly at random to draw an innovation. This innovation can be of three types: incremental, radical or imitative. More precisely, one has:

- With probability $\mu_{i n c}$ an incremental innovation is drawn, in which case a new supplier is drawn at random and added to the input mix (if the current number of suppliers is less than the maximum possible within the paradigm).

- With probability $\mu_{\text {rad }}$ a radical innovation, in which case a new technological paradigm $\left(e_{i}^{t+1}, \Upsilon_{i}^{t+1}\right)$ is drawn at random. The input mix $v_{i}^{t+1}$ then is reinitialized by drawing the new number of links according to a binomial distribution whose mean equals the mean number of links in the initial network, $v_{0}$. The maximal number of links for the new paradigm is itself drawn uniformly between $v_{\min }$ and $v_{\max }$, which are parameters of 
the model.

- With probability $\mu_{i m}$ the firm imitates one of its peers ${ }^{1}$ That is, it observes a firm $i^{\prime}$ at random and adopts its technology $\left(e_{i^{\prime}}, v_{i^{\prime}}\right)$ if it is more advanced than its current one in the sense that its more productive $e_{i^{\prime}}>e_{i}$.

- The network is then updated accordingly. That is if the firm has extended its input mix the corresponding number of new suppliers is drawn at random (and the corresponding entries are added to the adjacency matrix). If the firm has adopted a new technological paradigm but with a less elaborate input mix, the corresponding number of links (and the corresponding entries of the adjacency matrix) are selected uniformly at random and deleted.

- As a result of this process and of competition, some firms might lose incoming connections, consumers, up to the point where they no longer have any connection in the network. We consider that such a firm goes bankrupt and exits the market. Yet, to sustain competition in the economy, we assume that those exits are compensated by entries of new firms. New firms enter the market with a productivity equal to the average in the economy and with a number of suppliers drawn from a binomial distribution as in Gualdi and Mandel 2015].

These different mechanisms can be seen as micro-economic implementations of the macro-economic drivers of growth considered in the endogenous growth literature. On the one hand, the incremental/process innovation, which consists in adding inputs to the production process is very similar to the product variety model of endogenous growth à la Romer [1990], as well as to the infra-marginal approach to economic growth [see Yang and Borland, 1991] or of Adam Smith's original description of the effects of the division of labor. On the other hand, the product innovation process, which leads to a change of technological paradigm and to a direct increase of productivity implements a more radical form of innovation. It has strong similarities with Schumpeterian models of endogenous growth [see Aghion and Howitt, 1998, and references therein] in which series of monopolists sequentially push each other out of the market by developing more productive versions of a product. We investigate in the following the macroeconomic and distributional patterns that emerge from the interplay of these processes.

\footnotetext{
${ }^{1}$ Here and in the following, we always consider implicitly that the vector $\left(\mu_{i n c}, \mu_{i m}, \mu_{\text {rad }}\right)$ is normalized so that $\mu_{\text {rad }}+\mu_{i n c}+\mu_{i m}=1$
} 


\section{Innovation, growth and the evolution of pro- duction networks}

Our first objective is to characterize the impact of the different innovation processes under consideration on the macro-economic dynamics and the structural properties of the production network. Therefore, we perform series of montecarlo experiments under varying innovation regimes: incremental only, radical only, incremental and radical in combination. Building on the sensitivity analysis developed in Gualdi and Mandel [2015], we use as default in these experiments the set of parameters given in table 1, which are representative of the behavior the model in absence of innovation. Unless otherwise specified, we run simulation with five different random seeds for each parameter combination in order to average out stochasticity. However, we observe very little variability or macro-economic dynamics with varying seeds and therefore report only the results of a single simulation per set of parameters.

\begin{tabular}{|c|c|}
\hline Parameter & Value \\
\hline $\mathrm{m}$ & 2000 \\
\hline $\mathrm{S}$ & 5 \\
\hline $\mathrm{T}$ & 500000 \\
\hline$\rho_{\text {chg }}$ & 0.05 \\
\hline$\tau_{p}$ & 0.8 \\
\hline$\tau_{w}$ & 0.8 \\
\hline$\rho_{\text {inn }}$ & 0.001 \\
\hline$\theta$ & $1 / 2$ \\
\hline$v_{\min }$ & 10 \\
\hline$v_{\max }$ & 20 \\
\hline$v_{0}$ & 4 \\
\hline & \\
\hline
\end{tabular}

Table 1: Default parameter values

\subsection{Incremental Innovation}

We first focus on the dynamics of the model when the technological paradigm (i.e the maximal number of inputs) is fixed and only incremental innovation occurs, i.e the only source of productivity growth is the diversification of the input mix. In this setting, we perform a series of monte-carlo simulations focusing on the sensitivity of the model with respect to the rate of innovation and the elasticity of substitution. More precisely, we let $\rho_{\text {inn }}$ vary in $\left\{10^{-2}, 5.10^{-3}, 10^{-3}, 5.10^{-4}, 10^{-4}\right\}$ and $\theta$ vary in $\{3 / 5,1 / 2,1 / 4\}$. The technological paradigm for each firm is such that $e_{i}=1$ and $\bar{v}_{i}=20$. 

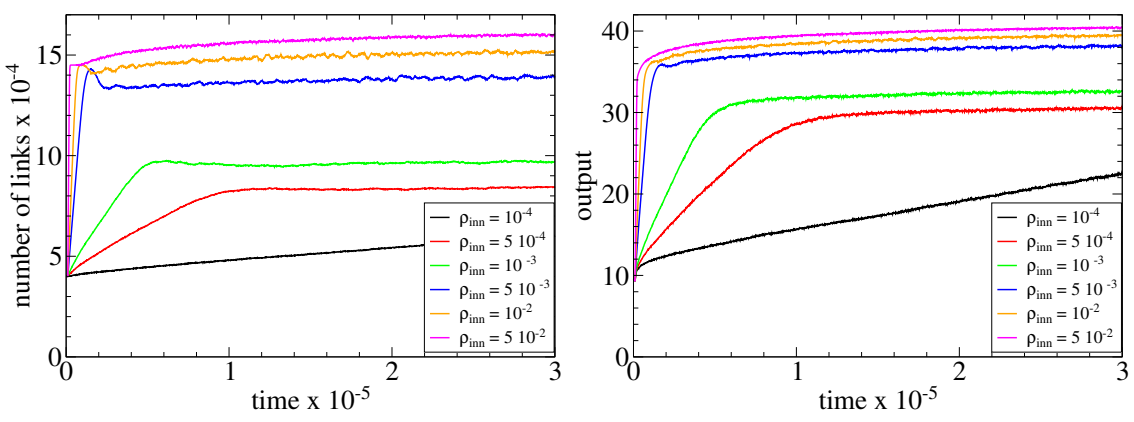

Figure 1: Evolution of the number of links (left) and of total output (right, log scale) for representative simulations corresponding to a $100 \%$ rate of incremental innovation, with varying innovation rates. Other parameters are set as in table 1.

The results of simulations, illustrated in figure 1, show that the qualitative behavior of the model is independent of the choice of parameters. In a setting where innovation ocurrs only within a fixed technological paradigm, increasing product variety is a transitory process: it lasts until the frontier of the technological paradigm is reached and connectivity saturates. In absence of saturation, the growth of the number of inputs ought to be linear as the number of inputs (tentatively) added to the production process is constant over time. However, the actual pattern is sublinear (see left panel of figure 1) given that the rate of success of these incremental innovations decreases as more firms approach the frontier of the technological paradigm. The right-panel of figure 1 presents the macro-economic counterpart of this connectivity pattern. Output grows at a decreasing rate during a transitory regime and then stabilizes.

It is clear that linear (or sublinear) increase in product variety can not lead to exponential growth, even if one abstracts away from the saturation process. In order to provide a quantitative approximation of the transient growth regime, we use the simplifying assumption that each input is used in similar quantity in the production process and has a normalized productivity of 1 . The quantity of output obtained by using $1 / n$ units of $n$ distinct varieties of inputs (and of a quantity of labor normalized to unity) is then given by:

$$
f(1,1 / n, \cdots, 1 / n)=\left(n(1 / n)^{\theta}\right)^{(1-\gamma) / \theta}=n^{(1 / \theta-1)(1-\gamma)}
$$

Thus, if one discards the saturation process and considers that the number of inputs grows linearly over time, i.e $n(t)=k t$, productivity (and production) shall grow as

$$
\phi(t)=(k t)^{(1 / \theta-1)(1-\gamma)}
$$

consistently with Wright's law [see Arrow, 1962, McNerney et al., 2011. In order to test the validity of this approximation in our framework, we have estimated the time dependency of output in the simulated data (before the establishment 
of the stationary regime) using a model of the form

$$
y=(a t)^{b}
$$

and compared the estimated $b$ exponent with the one predicted by equation 4 Table 2 illustrates our results. Equation 5 fits remarkably well the simulated data and the value of the estimated exponent is consistent with the one put forward in equation 4 , with a downward bias that can be explained by the progressive saturation process.

Table 2: Wright law exponent for varying elasticity

\begin{tabular}{lccc}
\hline \hline & \multicolumn{3}{c}{ Dependent variable: $\log (y)$} \\
\cline { 2 - 4 } & $(\theta=3 / 5)$ & $(\theta=1 / 2)$ & $(\theta=1 / 4)$ \\
\hline $\log (t)$ & $0.207^{* * *}$ & $0.321^{* * *}$ & $1.002^{* * *}$ \\
& $(0.0001)$ & $(0.0002)$ & $(0.001)$ \\
Constant & & & \\
& $-0.306^{* * *}$ & $-0.143^{* * *}$ & $0.776^{* * *}$ \\
& $(0.001)$ & $(0.002)$ & $(0.006)$ \\
\hline Observations & & & \\
$\mathrm{R}^{2}$ & 99,001 & 99,001 & 99,001 \\
Adjusted $\mathrm{R}^{2}$ & 0.965 & 0.965 & 0.966 \\
Residual Std. Error $(\mathrm{df}=98999)$ & 0.965 & 0.965 & 0.966 \\
\hline \hline Note: & 0.035 & 0.054 & 0.165 \\
\hline \multicolumn{3}{c}{${ }^{*} \mathrm{p}<0.1 ;{ }^{* *} \mathrm{p}<0.05 ;{ }^{* * *} \mathrm{p}<0.01$}
\end{tabular}

Hence, the incremental innovation process introduced in the model leads to a behavior which is consistent with the empirical evidence on the growth of productivity within a technological paradigm, which is summarized by Wright's law. Empirical estimates of Wright's law suggest an exponent close to $1 / 3$, corresponding to a value of $\theta$ of $3 / 5$ in our framework.

Another stylized fact of industrial dynamics that the model closely matches is that the degree distribution of firms' size, measured via their number of incoming connections, is scale free (see the left panel of Figure 2 and the related discussion in Gualdi and Mandel 2015]).

From a theoretical perspective, the incremental innovation process considered in this section is closely related to the product variety models à la Romer [1990]. However, in our setting, diversification is embedded at the core of the production process whereas in Romer's type of model the production process is represented in a much more aggregate way and diversification only concerns the production of a final good. From Romer's aggregate perspective, the assumption that product variety grows exponentially over time, which is required to sustain endogenous growth, does not seem overly problematic. In our micro-founded setting, exponential growth of product variety would imply either exponential 

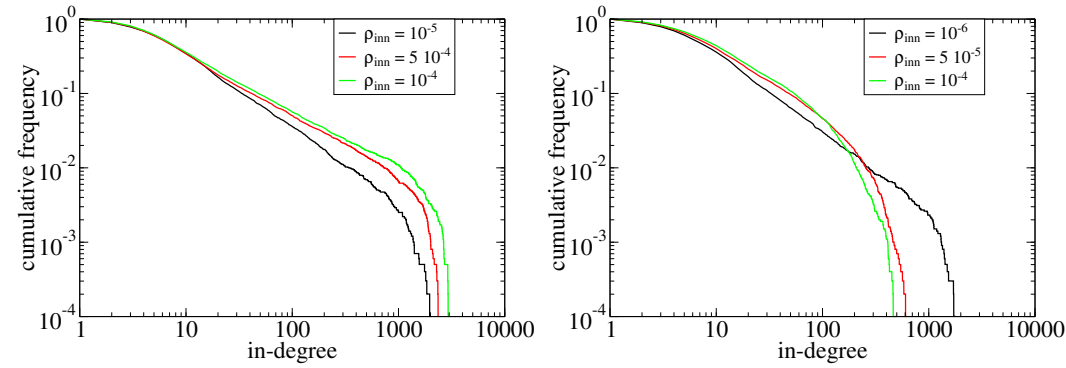

Figure 2: Distribution of in-degrees after $2.10^{6}$ periods for varying innovation rates. Left panel corresponds to incremental innovation only (subsection 4.1), right panel to radical innovation only (subsection 4.2). Other parameters are set as in table 1 .

growth of the network's density or of the number of firms. Both assumptions clearly are counter-factual. Hence, incremental innovation alone can not sustain endogenous growth except in the corner case where there is infinite complementary between inputs $(\theta \rightarrow 0)$ and the exponent of Wright's law $\beta=(1 / \theta-1)(1-\gamma)$ tends towards infinity [as in d'Autume and Michel, 1993 .

\subsection{Radical Innovation}

In a second series of experiments, we focus on the effects of radical innovation on industrial and macro-economic dynamics. Radical innovation yields a direct increase in productivity through product innovation. In this respect, it has similarities with Schumpeterian models of endogenous growth [see Aghion and Howitt, 1998, and references therein] in which series of monopolists sequentially push each other out of the market by developing more productive versions of a product hence putting the economy on an exponential growth path.

In order to characterize the impact of radical/product innovation in our setting, we perform a series of monte-carlo simulations in which it is the only source of innovation (i.e we set $\mu_{\text {rad }}=1$ while $\mu_{i n c}=\mu_{i m}=0$ ) and the total innovation rate $\rho_{\text {inn }}$ varies in $\left\{10^{-2}, 5.10^{-3}, 10^{-3}, 5.10^{-4}, 10^{-4}\right\}$.

The results of the simulations show that, from the macro-economic perspective, the qualitative behavior of the model is independent of the innovation rate. As illustrated in figure 3 radical innovation systematically leads to exponential growth. The growth regime establishes itself rapidly and is remarkably stable. Moreover, in absence of radical innovation, the average connectivity and the outdegree distribution of the network are also stable. The only source of volatility appears to be the entry and exit process of firms. 

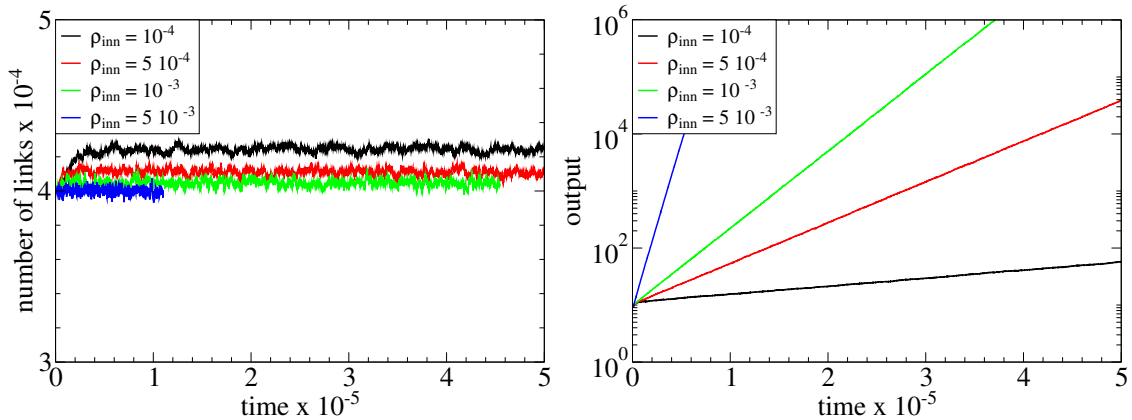

Figure 3: Evolution of the number of links (left) and of total output (right, $\log$ scale) for representative simulations corresponding to a $100 \%$ rate of radical innovation, with varying innovation rates. Other parameters are set as in table 1.

The impact of changes in the innovation rate materialize first by changes in the growth rate of the economy (see figure 3). From a more structural perspective, large innovation rates increase volatility in the growth patterns of firms. This materializes in the indegree distribution of firms. While the distribution is scale-free in presence of incremental innovation only, the presence of radical innovation affects the stability of large firms and shifts the distribution towards exponential tails for large value of the innovation rate $\rho_{i n n}$ (see right-panel of figure 22. This feature can be explained by the fact that the strength of competition increases with the speed at which new products, radical innovations, enter the market. Hence, the negative feedback effects on the growth of firms are much more important leading to the decrease of the tail of the distributions of sizes. This feature of the model might help clarify why conflicting evidences remain about the size distribution of firms (see e.g Cabral and Mata 2003 and Axtell 2001]). Shifts between different type of distributions might well depend on the growth pattern of the economy.

In all cases, the presence of heterogeneous firms is an emerging property of the model that is in strong contrast with the monopolistic feature of growth models à la Aghion and Howitt 1998 and brings the model much closer to empirical stylized facts about industrial dynamics. In the following, we investigate in more details how, through the interplay between incremental and radical innovations, the model can also account for complex dynamical patterns of output.

\subsection{Mixed innovation regimes and complex dynamics}

The experiments performed in the preceding subsections underline the complementary roles of incremental and radical innovations. Incremental innovation accounts for technological progress within a technological paradigm but saturates once the technological frontier is reached. Radical innovation accounts for 
the development of new products and paradigms and allows to sustain endogenous growth.

In this section, we investigate the interplay between these processes and in particular the impact on macro-economic and industrial dynamics of the competition between radical innovators and incumbents. This competition hardly materializes in presence of radical innovation only because all firms, incumbents and innovators, then have the same expected product variety $v_{0}$ (see subsection 3.3 and hence innovators always have a competitive advantage thanks to the increased productivity of their product. When both radical and incremental innovation are present, radical innovators, which initially have a low level of diversification/complexity ( $v_{0}$ in expectation), have to compete with incumbents that have climbed the complexity ladder with an older vintage of the product.

In order to investigate the impact of this competition, we have performed a series of experiments in which the ratio $\mu_{i n c} / \mu_{\text {rad }}$ between the rates of incremental and radical innovation varies in $\{[1,5,10,20,50]\}$. Other parameters are set as in table 1 and there is no imitation (i.e $\mu_{i m}=0$ ).

The results of the simulations show first that exponential growth is a very robust property of the dynamics: provided the rate of radical innovation is positive, the model eventually settles in an exponential growth regime after a transient period (see figure 4). The growth rate is an increasing function of the total innovation rate and a decreasing function of the ratio between incremental and radical innovation, i.e it increases with the rate of radical innovation. Conversely, the length of the transient decreases with the total innovation rate and increases with the ratio between incremental and radical innovation. In fact, a key parameter for the dynamics seems to be the expected frequency of radical innovations, which is proportional to $\rho_{i n n} \times \mu_{\text {rad }} / \mu_{i n c}$.

During the transient period, the dynamics of output and of connectivity, illustrated in figure 4, are very similar to those observed in presence of incremental innovation only (see section 4.1): the growth of output is driven by the increasing product variety in the production process (or equivalently by the increasing connectivity in the network). The growth pattern is also consistent with Wright's law. The transition to the stable regime occurs smoothly when the growth rate has reached an "equilibrium" value, which depends on the frequency of radical innovations. The end of the transient regime is also marked by the stabilization of connectivity. This "equilibrium" level of connectivity does not in general saturate the constraint of the technological paradigms (maximal number of suppliers) and decreases with the frequency of radical innovation (see figure 4). It is independent of the elasticity of substitution and of the maximal number of links. 

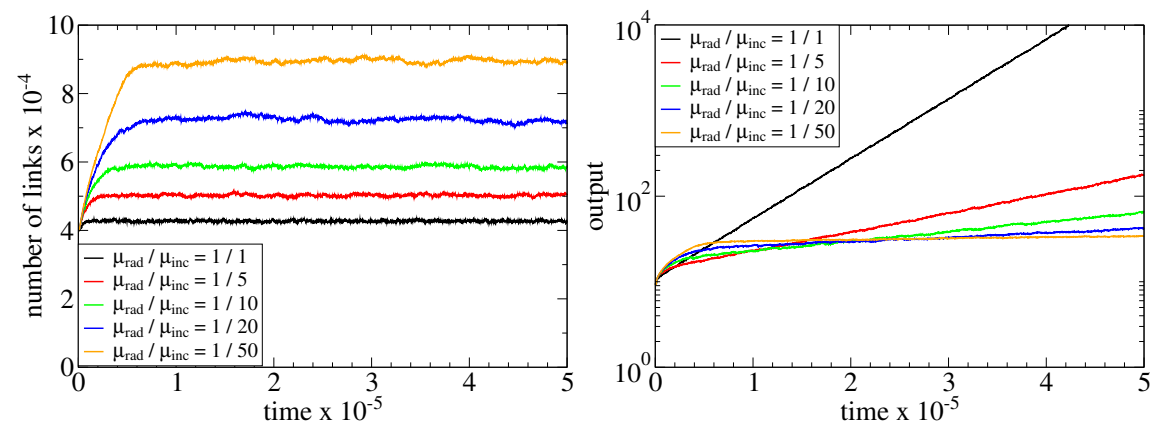

Figure 4: Evolution of the number of links (left) and of total output (right, $\log$ scale) for representative simulations with varying ratios between the rates of incremental and radical innovation (upper panel) and varying level of innovation rates (lower panel). Other parameters are set as in table 1

In fact, the equilibrium level of connectivity (or equivalently of product variety) is determined by the interplay between radical and product innovation. On the one hand, the frequency of incremental innovations determines a rate of increase of the number of links. On the other hand, radical innovations, if successful, lead to a decrease of the number of links. The frequency of success of radical innovations hence determine a rate of decrease of the number of links. The equilibrium level of connectivity corresponds to a level that balance creation and destruction of links. The larger the ratio between incremental and radical innovations, the higher this equilibrium level.

The dynamics of connectivity can then be explained by the presence of decreasing returns to connectivity/product variety (i.e $\theta>0$ ). During the transient period, while connectivity is lower than the equilibrium threshold, productivity gains induced by incremental innovation are large and can not be disrupted by radical innovations. While most firms' technologies are below this threshold, the increase in product variety is almost unconstrained. In the stable regime, returns to incremental innovation are lower, the model is at an equilibrium where productivity gains (per unit of time) induced by radical innovations are competitive with these induced by incremental innovations. Hence, the increase in connectivity due to incremental innovations is compensated by the decrease triggered by radical innovations.

With a large number of incremental and radical innovations, these mechanisms are only observed indirectly through the stability of the average level of connectivity. In order to characterize them more precisely, we focus on a more stylized version of the model where radical innovation is rare but gets amplified through imitation. Therefore, we run a second series of monte-carlo simulations in which innovation by imitation is enabled. We let the ratio between incremental and radical innovation, $\mu_{i m} / \mu_{\text {rad }}$, vary in $\{10,20,50\}$. We also let the ratio $\mu_{i n c} / \mu_{\text {rad }}$ vary in $\{1,10,20\}$ and set other parameters as in table 1 .

Our analysis mainly focuses on the properties of the stable regime, which 
is still characterized by exponential growth in the long-run. Yet, a key feature that emerges is the presence of technologically driven-business cycles, which materialize via fluctuations of the output and of the connectivity in the network, i.e of the average product variety of the technologies used (see figure 5, in particiular upper-left and lower-right panels).
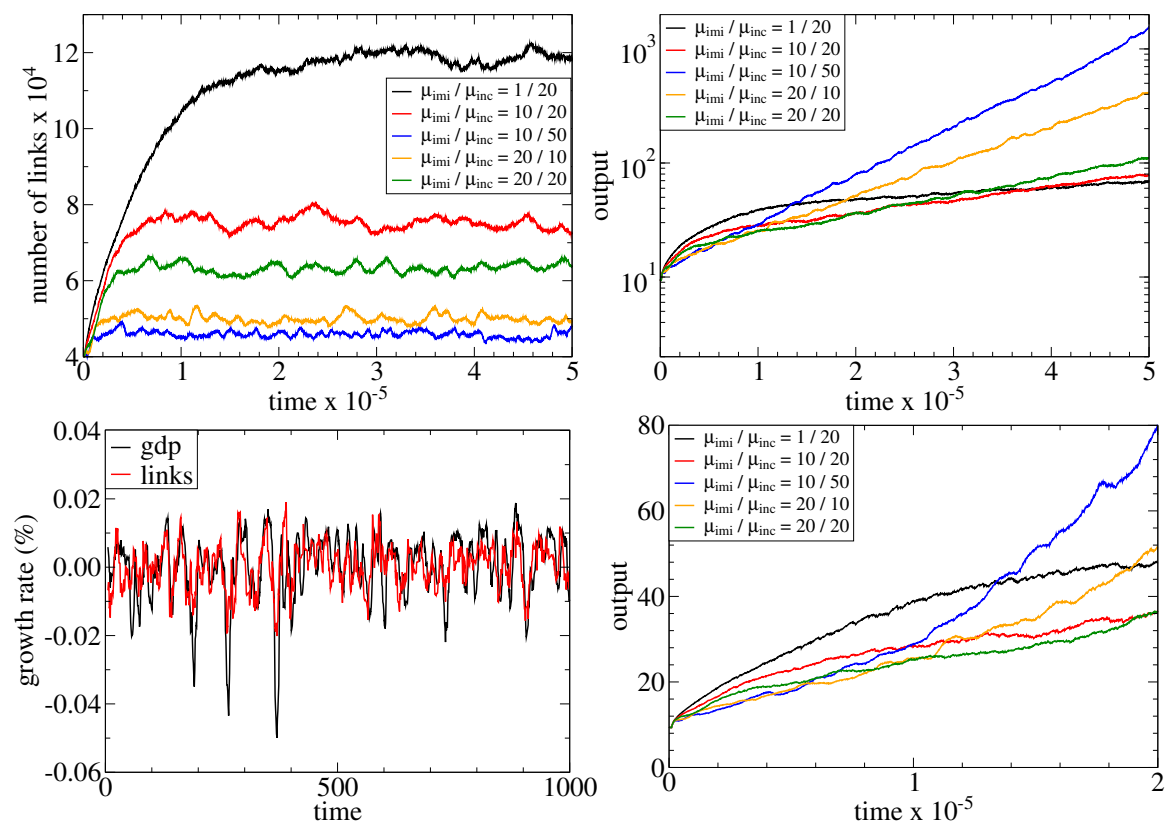

Figure 5: Evolution of the number of links (upper left) and of total output (upper and lower right) for representative simulations with varying imitation and incremental innovation rates. The lower left panel displays the joint evolution over 100000 periods of the growth rate of links and output for a representative simulation. Other parameters are set as in table 1.

These business cycles correspond to an amplified version of the interactions between the radical and incremental innovation processes analyzed above. The upswings of connectivity cycles correspond to the accumulation of incremental innovations as illustrated in the lower left panel of figure 5, which shows the very strong correlation between growth of output and connectivity. The downswings correspond to the occurence of radical innovations, amplified by imitation, that disrupt the industry. The amplitude and the period of these cycles increase with the $\mu_{i m} / \mu_{\text {rad }}$ ratio, that is as the frequency of radical innovations decreases and the role of imitation increases.

The fluctuations of output are strongly correlated with this of connectivity. Output grows with connectivity, i.e while technologies get more mature (see the lower left panel of figure 5). Accordingly the growth rate of output increases with the rate of incremental innovation (see the lower right panel of figure 5). Radical 
innovations destroy links and disrupt the production structure. Therefore, they have a negative impact on output in the short term. However, they pave the way for future growth as they allow for a new wave of incremental innovations to occur.

The contrast between figure 4 and 5 highlights the crucial role of imitation in the emergence of fluctuations. Indeed, imitation amplifies the synchronization of technological evolution among firms. It leads to the emergence, from the microeconomic behavior of distinct technological phases where product/radical and process/incremental innovation successively dominate. This pattern is reminiscent of empirical observations about the development of technologies described e.g in the Utterback-Abernathy model [see Utterback, 1994].

The structural evolution of the network is also aligned with key empirical facts about the demographics of firms. The distribution of firms' sizes, measured through their indegree distribution in figure 6, is characterized by fatter tails than normal, though the scale-free character is absent given that we consider here relatively large rate of innovation that imper the formation of very large firms. The outdegree distribution of firms in the right panel of figure 6 measures the variability of productivity (through variety in the input mix) in the population of firms. This distribution underlines the persistence of heterogeneity among firms in terms of productivity and the fact that this heterogeneity increases with the rate of incremental innovation that allows a deeper exploration of the technological paradigm.
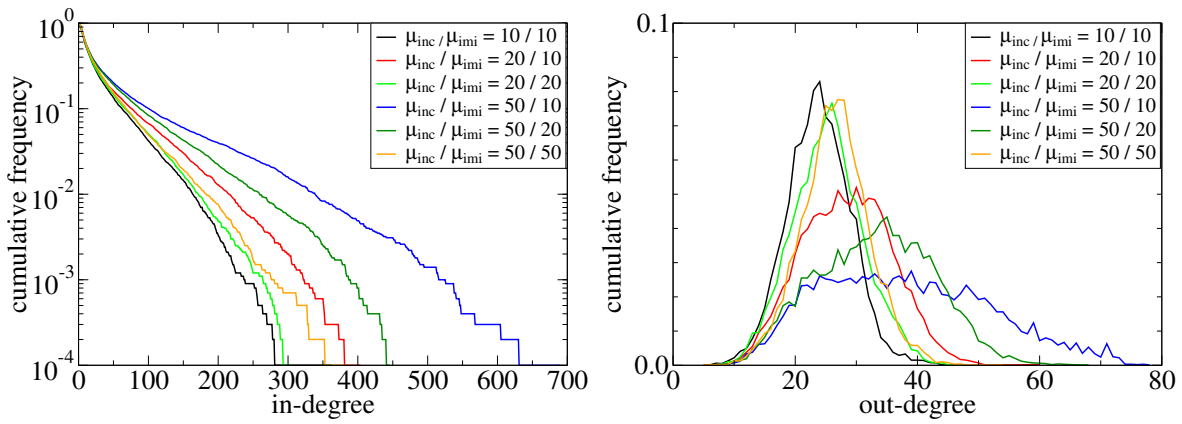

Figure 6: Distribution of in-degrees (left, log-linear) and out-degrees (right) after $2.10^{6}$ periods for varying imitation and incremental innovation rates. Other parameters are set as in table 1 .

\subsection{Firms' demographics}

More broadly, the model is able to replicate a wealth of stylized facts about industrial dynamics (see e.g Coad 2009]):

- As illustrated in the left panel Figure 7, growth rates of firms are distributed according to a "tent-shaped" double-exponential distribution (see 
Bottazzi and Secchi 2006]). Moreover, the right tail of the distribution thickens with the increasing share of imitative and radical innovation.

- There is a negative relation between the variance of growth rate and the size of firms. In absence of radical innovation, there moreover is a scaling relation, of the form $\sigma(s)=s^{-\beta}$ where $s$ is the size of the firm and $\sigma(s)$ is the variance of growth rates for firms of size $s$.

- As illustrated in the right panel of Figure 7, the distribution of product's productivity (the $e_{j} \mathrm{~s}$ ) is heterogeneous ; it exhibits much fatter tails in absence of imitation. Together with the above results about the outdegree distribution of firms, it implies that the model endogenously generate heterogeneity both in terms of process and of product productivity.
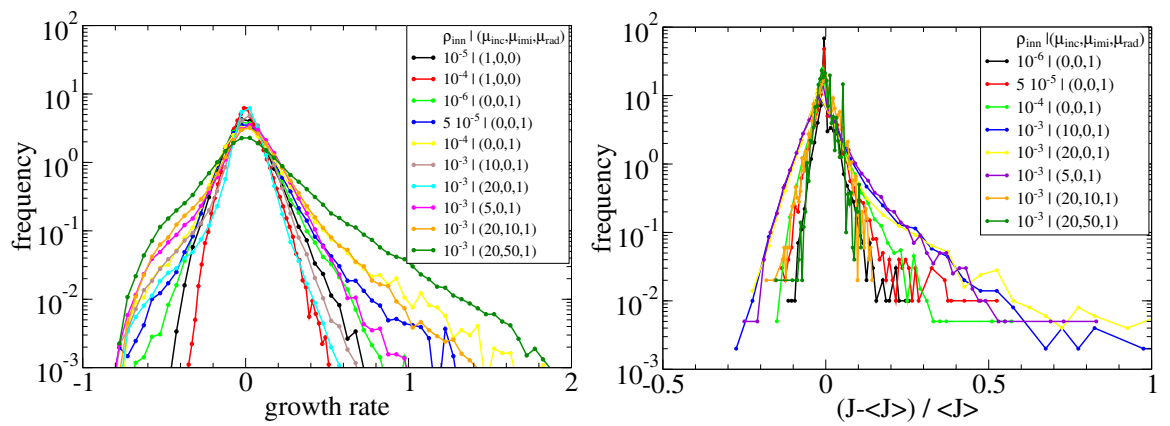

Figure 7: Distribution of growth rates (left) and of products' productivity (right) for varying rates of innovation.

\section{$5 \quad$ Policy experiments}

The preceding section puts forward the crucial role of radical innovation in sustaining growth in our model. This strongly echoes the emphasis on innovation and industrial policy in contemporary economies. A prominent example in the current policy debate is the energy industry where innovations in renewables energy production, which are crucial for climate change mitigation, are seen as potential drivers of "green" economic growth [see e.g Tàbara et al. 2013]. A key policy question then is whether growth can be stimulated through measures supporting radical innovations. In the context of energy markets, the main measures put in place were on the one hand feed-in tarifs, which consist in subsidizing the price paid to renewable energy producers and on the other hand preferential access to the market for renewable energy producers.

Accordingly, we investigate in the model the impact of price-based and quantity-based measures on the survival rate of radical innovators and on the growth rate of the economy. More precisely, we consider the following scenarios. 
- In the price-support scenario, which is akin to feed-in tariffs, the prices of radical innovators are subsidized during 200 periods after an innovation occurred. More precisely, if firm $i$ performed a radical innovation less than 200 periods ago, the price paid by its consumers is $\left(1-\tau_{\text {feed }}\right) p_{i}^{t}$ rather than $p_{i}^{t}$. We assume that the difference between buying and selling prices is financed by the government through external deficit ${ }^{2}$

- In the market-support scenario, akin to preferential market access, firms are set to rewire prioritarily to radical innovators when they update their suppliers (see equation 2). The length of time after their innovation for which firms are given priority access, $T_{p r}$ is the policy variable.

For each policy scenario, we perform a series of monte-carlo simulations where we let vary the policy parameter, respectively in $\{0.1,0.2,0.5\}$ for $\tau_{\text {feed }}$ and in $\{100,500,1000\}$ for $T_{p r}$. Other parameters are set as in section 4.3 with $\mu_{i m} / \mu_{\text {rad }} \in\{0,1\}$ and $\mu_{i n c} / \mu_{\text {rad }}=1$. Simulations are ran for five different seeds for each combination of parameters.
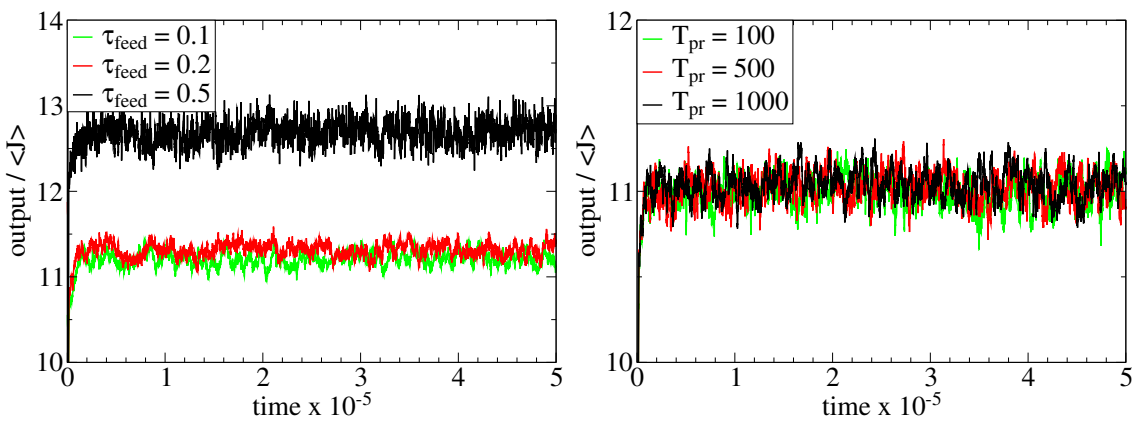

Figure 8: Evolution of outptut (normalized by average product productivity $J$ ) for the price-support (left) and the market-support (right) scenarios. In both cases, one has $\rho_{i n n}=10^{-3}, \mu_{i n c r}=\mu_{i m i}=\mu_{\text {rad }}$ and other parameters are set as in table 1.

As illustrated in Figure 8 and Table 3 respectively, only the pice-support policy has an impact on survival probabilities and hence on output. This suggests that price-support measures have, in our framework, a stronger impact on the competitive position of firms. Moreover, the market-support policy only shifts demand within the economy while the price-support policy provides, at the aggregate level, a subsidy to the economy by financing externally the price reduction for radical innovators. This subsidy can yield a demand-push and indirectly trigger multiplier effects.

The impact on output in the price-support scenario materializes, both with and without imitation, by the increase of the output per productivity unit ratio,

\footnotetext{
${ }^{2}$ In fact, everything goes as of the economy was receiving an external subsidy.
} 


\begin{tabular}{|c|c|c|c|}
\hline price-support scenario & & market-support scenario & 0 \\
\hline parameter & exit rate & parameter & exit rate \\
\hline$\mu_{i m}=0, \tau_{\text {feed }}=0.1$ & $3.10^{-2}$ & $\mu_{i m}=0, T_{p r}=100$ & $3.10^{-2}$ \\
\hline$\mu_{i m}=0, \tau_{\text {feed }}=0.2$ & $8.10^{-3}$ & $\mu_{i m}=0, T_{p r}=500$ & $4.10^{-2}$ \\
\hline$\mu_{i m}=0, \tau_{\text {feed }}=0.5$ & $5.10^{-4}$ & $\mu_{i m}=0, T_{p r}=1000$ & $5.10^{-2}$ \\
\hline$\mu_{i m}=1, \tau_{\text {feed }}=0.1$ & $2.10^{-2}$ & $\mu_{i m}=1, T_{p r}=100$ & $2.10^{-2}$ \\
\hline$\mu_{i m}=1, \tau_{\text {feed }}=0.2$ & $6.10^{-3}$ & $\mu_{i m}=1, T_{p r}=500$ & $3.10^{-2}$ \\
\hline$\mu_{i m}=1, \tau_{\text {feed }}=0.5$ & $3.10^{-4}$ & $\mu_{i m}=1, T_{p r}=1000$ & $4.10^{-2}$ \\
\hline
\end{tabular}

Table 3: Exit rate of radical innovators(per $10^{3}$ periods)

where the latter is measured by the average product productivity (see Figure 8). This implies that firms have, in average, a more efficient/diversified production process, i.e that they have seized more incremental innovations. This feature is clearly consistent with the decreased rate of exit for radical innovators: if firms leave longer, they have more opportunities to seize incremental innovations.

The impact on aggregate output is more ambiguous. Figure 9 suggests that the price-support policy has a negative impact in absence of imitation and a neutral (or slightly positive) impact in presence of imitation. This presumably is the counterpart of the increased lifespan of radical innovators. If incumbent innovators are more efficient, it is harder for a new radical innovation to succeed and hence the growth rate of productivity is reduced. This effect is partly offset by imitation, which allows to diffuse increased productivity directly among incumbents.

It is clearly inappropriate to draw direct policy conclusions from simple experiments performed in such a stylized framework. However, we would argue that our results underline that the impact of policy strongly depends on the kind of externalities in the economy under consideration. The main external effect on innovation in our framework is imitation for which only the most efficient producers matter. If we were to consider stronger complementarities between innovators, the survival of a larger share of innovators might have a much more significant impact on growth. 

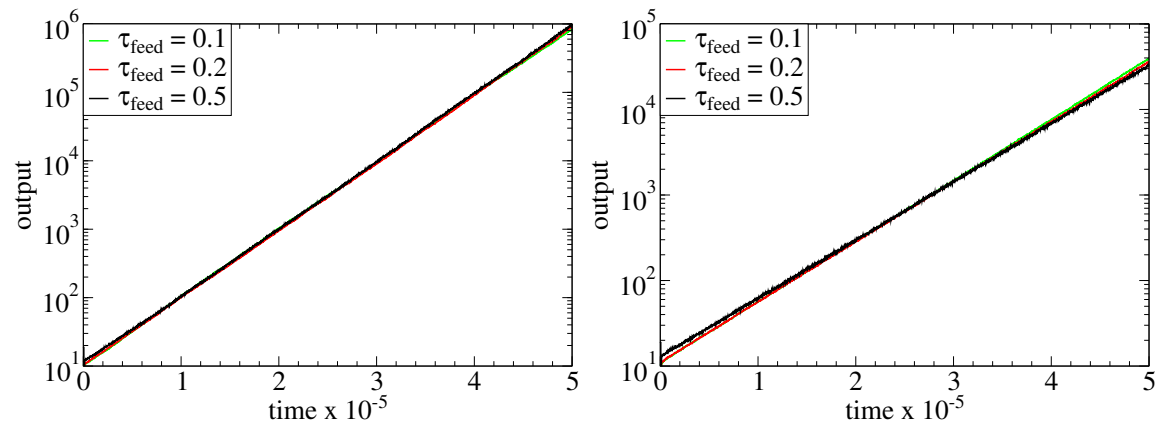

Figure 9: Evolution of outptut (log scale) for the price-support scenario with (left) and without (right) imitation.

\section{Concluding remarks}

We have developed a macro-economic agent-based model centered on the evolution of production networks. The structure of the network, i.e the structure of the market, constrains firm's behavior in the short-run and hence determines short-term economic dynamics. In turn, competition among firms and technological innovations govern the evolution of the network. Long-term macroeconomic dynamics hence emerge from the micro-economic interactions among firms.

From the theoretical point of view, our main innovation is to provide a detailed micro-economic representation of the production process, accounting for intermediary consumption, within a growing economy. Technological progress is embedded in the structure of the network and we consider two avenues for growth. Process innovation, which materializes through diversification of the input mix and hence increasing connectivity in the network. Product innovation, which induce a direct increase of productivity at the expense of a temporary loss of specialization in the production process and hence decreasing connectivity. These two processes can respectively be interpreted as the decentralization of the two workhorses of endogenous growth theory, product variety model à la Romer 1990 and "Schumpeterian" growth model à la Aghion and Howitt 1992], in a micro-economic setting with boundedly rational agents.

Considering innovation occurs at the micro-level and accounting for the local nature of interactions allow to reproduce a wealth of stylized facts that the aggregate nature of endogenous growth models discards by construction. Growth is exponential in the aggregate and follows Wright's law within a technological paradigm. The distribution of productivity among firms is heterogeneous. The distribution of firms' size exhibit fat-tails whose thickness depends on the aggregate rate of growth.

Additionally, imitation can lead to the synchronization of firms' innovative behavior and hence to the emergence of growth patterns in which pro- 
cess/incremental and product/radical innovation successively dominate, as in the Utterback-Abernathy model [see Utterback, 1994. This cyclicality of the innovation process induces technologically driven business cycles. Process innovation and increasing connectivity coincide with upswings, product innovation and decreasing connectivity with downswings.

The large number of stylized facts the model is able to reproduce and the richness of the dynamical patterns observed in simulations suggest that the model could be a useful testbed for the analysis of industrial and innovation policies, in particular in the context of the energy transition. In this view, we perform a first series of policy experiments in which we investigate the impact of feed-in tariffs and of priority access to the market on the survival rate of innovators and growth. Our results underline the fact that the impact of policy crucially depends on the nature of externalities among innovators. If imitation dominates, only the most efficient firms matter and these can survive without public support.

Yet, an important avenue for future research is to account for other form of external effects in the innovation process, for the role of institutions and for the broader socio-economic landscape in which innovation is developed [see e.g Saxenian, 1996, in these respects]. Another important aspect that requires further investigation is the role of the demand in the development of innovations. In this respect, it might be worth investigating the emergence of demand among heterogeneous households that might not necessarily be characterized by

preferences for goods but rather by Lancasterian preferences for characteristics Lancaster, 1966.

\section{References}

Daron Acemoglu, Vasco M. Carvalho, Asuman Ozdaglar, and Alireza TahbazSalehi. The network origins of aggregate fluctuations. Econometrica, 80 (5):1977-2016, 09 2012. URL http://ideas.repec.org/a/ecm/emetrp/ v80y2012i5p1977-2016.html.

$\mathrm{P}$ Aghion and P Howitt. A model of growth through creative destruction. Econometrica, 60(2), 1992.

Philippe Aghion and Peter Howitt. Endogenous growth theory. 1998.

Kenneth J Arrow. The economic implications of learning by doing. The review of economic studies, pages 155-173, 1962.

Philip Auerswald, Stuart Kauffman, José Lobo, and Karl Shell. The production recipes approach to modeling technological innovation: An application to learning by doing. Journal of Economic Dynamics and Control, 24(3):389450,2000 .

Robert L Axtell. US firm sizes are zipf distributed. Science, 93:1818-1820, 2001. 
Per Bak, Chao Tang, and Kurt Wiesenfeld. Self-organized criticality: An explanation of the 1/f noise. Physical review letters, 59(4):381, 1987.

Stefano Battiston, Domenico Delli Gatti, Mauro Gallegati, Bruce Greenwald, and Joseph E. Stiglitz. Credit chains and bankruptcy propagation in production networks. Journal of Economic Dynamics and Control, 31 (6):2061-2084, June 2007. URL http://ideas.repec.org/a/eee/dyncon/ v31y2007i6p2061-2084.html

Giulio Bottazzi and Angelo Secchi. Explaining the distribution of firm growth rates. The RAND Journal of Economics, 37(2):235-256, 2006.

Luis MB Cabral and Jose Mata. On the evolution of the firm size distribution: Facts and theory. American economic review, pages 1075-1090, 2003.

Vasco M Carvalho. From micro to macro via production networks. The Journal of Economic Perspectives, 28(4):23-47, 2014.

Vasco M Carvalho and Nico Voigtländer. Input diffusion and the evolution of production networks. Technical report, National Bureau of Economic Research, 2014.

Tommaso Ciarli, André Lorentz, Maria Savona, and Marco Valente. The effect of consumption and production structure on growth and distribution. a micro to macro model. Metroeconomica, 61(1):180-218, 2010.

Alex Coad. The growth of firms: A survey of theories and empirical evidence. Edward Elgar Publishing, 2009.

Antoine d'Autume and Philippe Michel. Endogenous growth in arrow's learning by doing model. European Economic Review, 37(6):1175-1184, 1993.

Herbert Dawid, Simon Gemkow, Philipp Harting, Sander van der Hoog, and Michael Neugart. The eurace@ unibi model: An agent-based macroeconomic model for economic policy analysis. Technical report, Working paper. Universität Bielefeld, 2011.

Herbert Dawid, Philipp Harting, and Michael Neugart. Economic convergence: Policy implications from a heterogeneous agent model. Journal of Economic Dynamics and Control, 44:54-80, 2014.

Giovanni Dosi and Richard R Nelson. Technical change and industrial dynamics as evolutionary processes. Handbook of the Economics of Innovation, 1:51$127,2010$.

Giovanni Dosi, Giorgio Fagiolo, and Andrea Roventini. Schumpeter meeting keynes: A policy-friendly model of endogenous growth and business cycles. Journal of Economic Dynamics and Control, 34(9):17481767, September 2010. URL http://ideas.repec.org/a/eee/dyncon/ v34y2010i9p1748-1767.html. 
Giovanni Dosi, Giorgio Fagiolo, Mauro Napoletano, and Andrea Roventini. Income distribution, credit and fiscal policies in an agent-based keynesian model. Journal of Economic Dynamics and Control, 37(8):1598-1625, 2013.

Giovanni Dosi, Giorgio Fagiolo, Mauro Napoletano, Andrea Roventini, and Tania Treibich. Fiscal and monetary policies in complex evolving economies. Journal of Economic Dynamics and Control, 52:166-189, 2015.

Wilfred J Ethier. National and international returns to scale in the modern theory of international trade. The American Economic Review, pages 389405, 1982.

Koen Frenken. A fitness landscape approach to technological complexity, modularity, and vertical disintegration. Structural Change and Economic Dynamics, 17(3):288-305, 2006a.

Koen Frenken. Technological innovation and complexity theory. Economics of Innovation and New Technology, 15(2):137-155, 2006b.

Stanislao Gualdi and Antoine Mandel. On the emergence of scale-free production networks. arXiv preprint arXiv:1509.01483, 2015.

Matthew O Jackson and Brian W Rogers. Meeting strangers and friends of friends: How random are social networks? The American economic review, pages $890-915,2007$.

Stuart Kauffman. The origins of order: Self organization and selection in evolution. Oxford University Press, USA, 1993.

Stuart Kauffman, José Lobo, and William G Macready. Optimal search on a technology landscape. Journal of Economic Behavior \&3 Organization, 43(2): 141-166, 2000.

Kelvin J Lancaster. A new approach to consumer theory. The journal of political economy, pages 132-157, 1966.

Antoine Mandel, Carlo Jaeger, Steffen Fürst, Wiebke Lass, Daniel Lincke, Frank Meissner, Federico Pablo-Marti, and Sarah Wolf. Agent-based dynamics in disaggregated growth models. Documents de travail du Centre d'Economie de la Sorbonne 10077, Université Panthéon-Sorbonne (Paris 1), Centre d'Economie de la Sorbonne, September 2010. URL http://ideas. repec.org/p/mse/cesdoc/10077.html

James McNerney, J Doyne Farmer, Sidney Redner, and Jessika E Trancik. Role of design complexity in technology improvement. Proceedings of the National Academy of Sciences, 108(22):9008-9013, 2011.

Richard R Nelson and G Winter Sidney. An evolutionary theory of economic change, 1982. 
Paul M Romer. Endogenous technological change. Journal of Political Economy, 98(5 pt 2), 1990.

Pier Saviotti and Andreas Pyka. Product variety, competition and economic growth. Journal of Evolutionary Economics, 3(18):323-347, 2008.

Pier P Saviotti et al. Technological evolution, variety and the economy. Books, 1996.

AnnaLee Saxenian. Regional advantage. Harvard University Press, 1996.

Gerald Silverberg and Bart Verspagen. A percolation model of innovation in complex technology spaces. Journal of Economic Dynamics and Control, 29 (1):225-244, 2005.

Joan David Tàbara, Diana Mangalagiu, Roland Kupers, Carlo C Jaeger, Antoine Mandel, and Leonidas Paroussos. Transformative targets in sustainability policy making. Journal of Environmental Planning and Management, 56 (8):1180-1191, 2013.

James M. Utterback. Mastering the Dynamics of Innovation: How Companies Can Seize Opportunities in the Face of Technological Change. Harvard Business School Press, Boston, MA, USA, 1994. ISBN 0-87584-342-5.

Gérard Weisbuch and Stefano Battiston. From production networks to geographical economics. Journal of Economic Behavior 85 Organization, 64(3): 448-469, 2007.

Sarah Wolf, Steffen Fuerst, Antoine Mandel, Wiebke Lass, Daniel Lincke, Federico Pablo-Marti, and Carlo Jaeger. A multi-agent model of several economic regions. Environmental Modelling and Software, 44:25 - 43, 2013. ISSN 13648152. doi: 10.1016/j.envsoft.2012.12.012. URL http://www.sciencedirect. com/science/article/pii/S1364815213000029.

Theodore P Wright. Factors affecting the cost of airplanes. Journal of the aeronautical sciences, 3(4):122-128, 1936.

Xiaokai Yang and Jeff Borland. A microeconomic mechanism for economic growth. Journal of Political Economy, pages 460-482, 1991.

\section{A General Equilibrium and Production Networks}

\section{A.1 A general equilibrium economy}

One can associate to a production network $A$ a general equilibrium economy as follows:

Definition 1 The general equilibrium economy $\mathcal{E}(A)$ is defined by the given of: 
- A representative household supplying one unit of labor and having preferences represented by the Cobb-Douglas utility functiion $u\left(x_{1}, \cdots, x_{m}\right)=$ $\prod_{i=1}^{m} x_{i}^{\alpha_{0, i}}$

- A set of firms $M$ with production functions of the form

$$
f_{i}\left(x_{0},\left(x_{j}\right)_{j=1, \cdots, n_{i}}\right)=x_{0}^{\alpha}\left(\sum_{j=1}^{n_{i}} x_{j}^{\theta}\right)^{(1-\alpha) / \theta}
$$

- A production network $A$ consistent with equation (6) in the sense that for all $i \in M, \sum_{j=1}^{m} a_{i, j}=n_{i}$.

\section{A.2 Out-of-equilibrium Dynamics}

For a given network, the dynamics of prices and output follow from the application of simple behavioral rules. More precisely, given a production network $A$ the dynamics of wealth $w_{i}^{t} \in \mathbb{R}_{+}$, output $q_{i}^{t} \in \mathbb{R}_{+}$and prices $p_{i}^{t} \in \mathbb{R}_{+}$within period $t$ are determined as follows.

1. Each agent $i$ receives the nominal demand $\sum_{j \in N} \alpha_{i, j}^{t} w_{j}^{t}$, which is implied by the current structure of the supply network

2. Agents adjust their prices frictionally towards their market-clearing values according to:

$$
p_{i}^{t}=\tau_{p} \bar{p}_{i}^{t}+\left(1-\tau_{p}\right) p_{i}^{t-1}
$$

where $\tau_{p} \in[0,1]$ is a parameter measuring the speed of price adjustment and, given the nominal demand $\sum_{j \in N} \alpha_{i, j}^{t} w_{j}^{t}$ and the output stock $q_{i}^{t}, \bar{p}_{i}^{t}$ is the market clearing price for firm $i$, that is:

$$
\bar{p}_{i}^{t}=\frac{\sum_{j \in N} \alpha_{i, j}^{t} w_{j}^{t}}{q_{i}^{t}}
$$

3. Whenever $\tau_{p}<1$ markets do not clear (except if the system is at a stationary equilibrium). In case of excess demand, we assume that clients are rationed proportionally to their demand. In case of excess supply, we assume that the amount $\bar{q}_{i}^{t}:=\sum_{j \in N} \alpha_{i, j}^{t} w_{j}^{t} / p_{i}^{t}$ is actually sold and that the rest of the output is stored as inventory. Together with production occurring on the basis of purchased inputs, this yields the following evolution of the product stock:

$$
q_{i}^{t+1}=q_{i}^{t}-\bar{q}_{i}^{t}+f_{i}\left(\frac{\alpha_{0, i}^{t} w_{i}^{t}}{p_{0}^{t}},\left(\frac{\alpha_{j, i}^{t} w_{i}^{t}}{p_{j}^{t}}\right)_{j \in \Sigma_{i}\left(A^{t}\right)}\right)
$$

Note that in the case where $\tau_{p}=1$, markets always clear (one has $\bar{q}_{i}^{t}=q_{i}^{t}$ ) and equation (9) reduces to

$$
q_{i}^{t+1}=f_{i}\left(\frac{\alpha_{0, i}^{t} w_{i}^{t}}{p_{0}^{t}},\left(\frac{\alpha_{j, i}^{t} w_{i}^{t}}{p_{j}^{t}}\right)_{j \in \Sigma_{i}\left(A^{t}\right)}\right)
$$


4. As for the evolution of agents' wealth, it is determined on the one hand by their purchases of inputs and their sales of output. On the other hand, we assume that the firm sets its expenses for next period at $(1-\lambda)$ times its current revenues and distributes the rest as dividends to the representative household. That is one has:

$$
\begin{gathered}
\forall i \in M, w_{i}^{t+1}=(1-\lambda) \bar{q}_{i}^{t} p_{i}^{t} \\
w_{0}^{t+1}=q_{0}^{t} p_{0}^{t}+\lambda \sum_{i \in M} \bar{q}_{i}^{t} p_{i}^{t}
\end{gathered}
$$

Note that equation 12 can be interpreted as assuming that firms have myopic expectations about their nominal demand (i.e they assume they will face the same nominal demand next period) and target a fixed profit/dividend share $\lambda \in(0,1)$.

5. As for the evolution of input shares, agents adjust frictionally their input combinations towards the cost-minimizing value according to:

$$
\alpha_{i}^{t+1}=\tau_{w} \bar{\alpha}_{i}^{t}+\left(1-\tau_{w}\right) \alpha_{i}^{t}
$$

where $\tau_{w} \in[0,1]$ measures the speed of technological adjustment and $\bar{\alpha}_{i}^{t} \in$ $\mathbb{R}^{M}$ denotes the optimal input weights for firm $i$ given prevailing prices. Those weights are defined as the solution to the following optimization problem:

$$
\left\{\begin{array}{cc}
\max & f_{i}\left(\frac{\alpha_{0}, i}{p_{0}^{t}},\left(\frac{\alpha_{j}, i}{p_{j}^{t}}\right)_{j \in \Sigma_{i}\left(A^{t}\right)}\right) \\
\text { s.t } & \sum_{j \in \Sigma_{i}\left(A^{t}\right)} \alpha_{j, i}=1
\end{array}\right.
$$

\section{A.3 Convergence}

These behavioral rules in fact define out-of-equilibrium dynamics in the economy $\mathcal{E}(A)$. Their asymptotic properties are extensively studied in Gualdi and Mandel, 2015. In particular, for a fixed network and over a vast region of the parameter space, one observes convergence to a general equilibrium of the underlying economy with a fixed mark-up rate $\lambda$. It corresponds to general equilibrium in the common-sense if $\lambda=0$ and is defined as follows:

Definition $2 A \lambda$-mark-up equilibrium of the economy $\mathcal{E}(A)$ is a collection of prices $\left(p_{0}^{*}, \cdots, p_{n}^{*}\right) \in \mathbb{R}_{+}^{M}$, production levels $\left(q_{0}^{*}, \cdots, q_{n}^{*}\right) \in \mathbb{R}_{+}^{M}$ and commodity flows $\left(x_{i, j}^{*}\right)_{i, j=0 \cdots n} \in \mathbb{R}_{+}^{M \times M}$ such that:

- Markets clear. That is for all $i \in M$, one has

$$
q_{i}^{*}=\sum_{j=1}^{M} x_{i, j}^{*} .
$$


- The representative consumer maximizes his utility. That is $\left(q_{0}^{*},\left(x_{0, j}^{*}\right)_{j=1, \cdots, n}\right)$ is a solution to

$$
\left\{\begin{array}{c}
\max u_{i}\left(\left(x_{0, j}\right)_{j=1, \cdots, n}\right) \\
\text { s.t } \sum_{j=1}^{n} p_{j}^{*} x_{0, j}^{*} \leq 1
\end{array}\right.
$$

(with the price of labor normalized to 1 )

- Production costs are minimized. That is for all $i \in M,\left(x_{i, j}^{*}\right)_{j=0 \cdots n}$ is the solution to

$$
\left\{\begin{array}{cc}
\min & \sum_{j \in \Sigma_{i}(A)} p_{j}^{*} x_{j} \\
\text { s.t } & f_{i}\left(x_{j}\right) \geq q_{i}^{*}
\end{array}\right.
$$

- Prices are set as a mark-up over production costs at rate $\frac{\lambda}{1-\lambda}$. That is one has for all $i \in N$ :

$$
p_{i}^{*}=\left(1+\frac{\lambda}{1-\lambda}\right) \frac{\sum_{j \in \Sigma_{i}(A)} p_{j}^{*} x_{i, j}^{*}}{q_{i}^{*}}
$$

